\title{
Direct oral anticoagulants for the treatment and prevention of venous thromboembolism in patients with cancer: current evidence
}

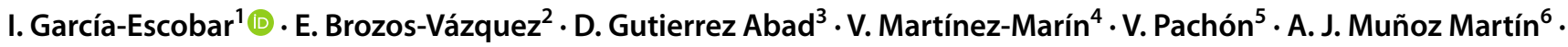 \\ Cancer and Thrombosis Section of the Spanish Society of Medical Oncology (SEOM)
}

Received: 8 May 2020 / Accepted: 28 September 2020 / Published online: 18 November 2020

(c) The Author(s) 2020

\begin{abstract}
Venous thromboembolic disease (VTED) is a common and clinically important complication in patients with cancer, contributing to its mortality and morbidity. Direct oral anticoagulant agents (DOACs), including direct thrombin inhibitors and direct factor Xa inhibitors, are as effective as vitamin $\mathrm{K}$ antagonists for the treatment of VTED and are associated with less frequent and severe bleeding. They have advantages over low-molecular-weight heparin, but comparative long-term efficacy and safety data are lacking for these compounds. Recent randomized clinical trials suggest a role for DOACs in the treatment of VTED in patients with cancer. This review will discuss the existing evidence and future perspectives on the role of DOACs in the treatment of VTE based on the current evidence about their overall efficacy and safety and the limited information in patients with cancer; in addition, we will briefly review their pharmacokinetic properties with special reference to potential interactions.
\end{abstract}

Keywords Venous thromboembolic disease $\cdot$ Cancer $\cdot$ Direct oral anticoagulant agents $\cdot$ Efficacy $\cdot$ Safety

\section{Introduction}

Venous thromboembolic disease (VTED) is a common and clinically important complication in patients with cancer [1]. Coagulation and cancer interact bidirectionally in a vicious circle in which the tumor is able to activate coagulation by

I. García-Escobar

naxto@hotmail.com

1 Servicio de Oncología, Hospital General Universitario de Ciudad Real, Calle Obispo Rafael Torija, s/n, 13005 Ciudad Real, Spain

2 Servicio de Oncología Médica, Complejo Hospitalario Universitario de Santiago de Compostela, Santiago de Compostela, Spain

3 Servicio de Oncología, Hospital Universitario de Fuenlabrada, Fuenlabrada, Spain

4 Servicio de Oncología Médica, Hospital Universitario La Paz, Madrid, Spain

5 Servicio de Oncología Médica, Hospital Universitario Ramon Y Cajal, IRYCIS, CIBERONC, Madrid, Spain

6 Servicio de Oncología Médica, Hospital General Universitario Gregorio Marañón, Universidad Complutense, Madrid, Spain producing procoagulant factors (e.g., tissue factors, cancer procoagulant proteins, microparticles, molecules of adhesion, proangiogenic factors and cytokines); these factors promote the generation of thrombin and the formation of fibrin which, in turn, favor the progression and growth of the tumor [2].

In cancer patients, factors that may be related to the increased risk of VTED could be patient-related (age, sex, race, comorbidities, immobilization, and previous history of thrombosis), cancer-related (tumor location, tumor stage, histology, and time from diagnosis) and treatment-related (periods of hospitalization and surgery, chemotherapy, antiangiogenic agents, and intravascular devices, such as central venous catheters) [3].

Currently, VTED in patients with cancer is particularly challenging, with higher rates of recurrence and major bleeding than in noncancer patients [4]. These complications are very relevant, because they contribute to mortality and morbidity. Evidence-based guidelines recommend the use of low-molecular-weight heparin (LMWH) for long-term anticoagulant treatment [5-7]. Despite clinical consensus and clinical guideline recommendations, LMWH treatment is underused [8-11], which is principally due to problems with administration, cost and patient preference. 
LMWHs were developed in the late seventies and early eighties of the last century. They are obtained from the chemical or enzymatic depolymerization of heparin so that the molecules reach a molecular weight of 4000-5000 Daltons. The anticoagulant effect is due to the activation of antithrombin, which promotes the inactivation of factor Xa (and, to a lesser extent, thrombin). Compared with unfractionated heparin (UFH), which is administered intravenously, the major advantages of LMWHs are their subcutaneous administration and similar antithrombotic efficacy [12].

Direct oral anticoagulant agents (DOACs), including direct thrombin inhibitors (dabigatran) and direct factor Xa inhibitors (rivaroxaban, apixaban, edoxaban and betrixaban), are as effective as vitamin $\mathrm{K}$ antagonists (VKAs) for the treatment of VTED and are associated with less frequent and severe bleeding [12-14]. Three of these molecules (namely, apixaban, edoxaban and rivaroxaban) target activated factor $\mathrm{X}$, and one molecule (i.e., dabigatran) is directed against activated factor II, thrombin. They are employed to prevent and treat thromboembolic events [i.e., deep vein thrombosis (DVT) or acute pulmonary embolism (PE)] or to prevent stroke and systemic embolization in cases of nonvalvular atrial fibrillation (NVAF).

They have advantages over LMWH, including a fixeddose regimen and oral intake, predictable pharmacology and anticoagulation, and no need for regular laboratory monitoring. However, the efficacy and safety of DOACs compared with long-term LMWH have not been established, and until recently, there were limited clinical data on this topic, especially in patients suffering from cancer-associated venous thromboembolism (VTE).

In this review, we aimed to provide the most recent evidence and future perspectives regarding DOACs for the management of VTE in patients with cancer, as well as to make some recommendations based on that evidence.

\section{Methods}

A literature search was performed in MEDLINE, The Cochrane Library, and EMBASE looking for studies published from database inception up to May 2019 on the new DOACs dabigatran, apixaban, rivaroxaban, and edoxaban. Comprehensive searches for conference abstracts were also carried out. Eligible study designs included observational analytical studies (i.e., case-control and cohort studies), randomized controlled trials, and meta-analyses of clinical trials. No language restriction was used. The eligibility criteria for being included in this review were: (1) cancer patients with a diagnosis of acute VTE; (2) reported outcomes comparing new DOACs in cancer patients; and (3) data of VTE or acute bleeding reported for up to 3 months of time.
From each study, we extracted and tabulated details on study source type, design, patients with acute VTE, mean age in years, percentage of female patients, estimated recurrent VTE risk, estimated bleeding risk (major, nonmajor and clinically relevant nonmajor bleeding), VTE events, and duration of anticoagulation.

\section{Role of new anticoagulants}

\section{Dabigatran}

Dabigatran is a small molecule prodrug that shows no pharmacological activity. After oral administration, dabigatran etexilate is rapidly absorbed and transformed into dabigatran by esterase-catalyzed hydrolysis in plasma and in the liver, constituting the main active substance in plasma. Dabigatran is a potent, competitive and reversible direct thrombin inhibitor that inhibits free thrombin, fibrin-attached thrombin and thrombin-induced platelet aggregation [15].

It is currently indicated for the primary prevention of venous thromboembolic episodes in adult patients undergoing scheduled total hip replacement surgery or total knee replacement surgery [16-19]. Venker et al. [20] published a meta-analysis analyzing the efficacy of $150 \mathrm{mg}$ dabigatran. The relative risk (RR) of VTE was lowest for $30 \mathrm{mg}$ edoxaban once daily $[0.49 ; 95 \%$ confidence interval (CI), $0.32-0.75], 2.5 \mathrm{mg}$ fondaparinux once daily $(0.53 ; 95 \% \mathrm{CI}$ $0.45-0.63)$, and $10 \mathrm{mg}$ rivaroxaban once daily $(0.55 ; 95 \%$ CI 0.46-0.66) and was highest for dabigatran $(1.19$; $95 \%$ CI $0.98-1.44)$, with a similar safety profile in terms of major/ clinically significant bleeding with a HR of 1.22 (95\% CI $0.89-1.67 ; p=0.22$ ) and $220 \mathrm{mg}$ dabigatran with an HR of 1.04 (95\% CI $0.87-1.24 ; p=0.68$ ), with major/clinically significant bleeding having an HR of 1.14 (95\% CI 0.93-1.4; $p=0.20$ ) compared to enoxaparin (most common dosage of $40 \mathrm{mg}$ once daily). It is also indicated for the prevention of stroke and systemic embolism in adult patients with NVAF with one or more risk factors [21,22], for the treatment of DVT and PE, and for the prevention of DVT and PE recurrence in adults [23-25]. The usual dosage is between 110 and $220 \mathrm{mg}$ orally per day based on the time since surgery and with adjustments for renal function, age and concomitant medication (especially with the intake of amiodarone, verapamil and quinidine). Currently, there are no published randomized clinical trials evaluating its use in patients with VTED and cancer.

\section{Rivaroxaban}

Rivaroxaban is a highly selective direct factor Xa inhibitor. The inhibition of factor Xa interrupts the intrinsic and 
extrinsic pathways of the blood coagulation cascade, inhibiting thrombin formation [26].

Rivaroxaban, coadministered with acetylsalicylic acid (ASA) alone or with ASA plus clopidogrel or ticlopidine, is indicated for the prevention of atherothrombotic events in adult patients after acute coronary syndrome (ACS) with elevated cardiac biomarkers [27]. Coadministration with ASA is indicated for the prevention of atherothrombotic events in adult patients with coronary artery disease (CAD) or symptomatic peripheral artery disease (PAD) at high risk of ischemic events [28]. It also shares the abovementioned indications of dabigatran [29-34]. The recommended dosage is $2.5 \mathrm{mg}$ orally twice daily.

Regarding VTE prophylaxis in orthopedic surgeries, we note the aforementioned meta-analysis [20], with a lower RR of VTE for rivaroxaban (0.55 (95\% CI 0.46-0.66; $p<0.001)$, significantly increasing the risk of clinically relevant bleeding with an HR of 1.27 (95\% CI 1.01-1.59; $p=0.039$ ) but not of major bleeding [HR 1.88 (95\% CI 0.67-5.29; $p=0.23)]$.

Regarding VTE prophylaxis in stroke NVAF, the Cochrane Collaboration [35] published a review on the activity of factor Xa inhibitors, collecting data from 13 studies with an HR of 0.89 (95\% CI 0.82-0.97) for systemic stroke/emboli, significantly reducing the risk of intracranial hemorrhage (HR 0.47, 95\% CI 0.40-0.56) and major bleeding (HR 0.76, 95\% CI 0.60-0.96), although the results were less robust.

\section{Apixaban}

Apixaban is an oral, reversible, direct and highly selective inhibitor of factor Xa. It does not require antithrombin III for antithrombotic activity. Apixaban inhibits free and clotbound factor Xa and prothrombinase activity. It has no direct effect on platelet aggregation but indirectly inhibits thrombin-induced platelet aggregation [36]. It is also indicated for the prevention of VTE in adult patients who have undergone elective hip or knee replacement surgery, for the prevention of stroke and systemic embolism in adult patients with NVAF with one or more risk factors, and for the treatment of DVT and PE, as well as the prevention of DVT and PE recurrence in adult patients [37-39].

\section{Edoxaban}

Edoxaban is a highly selective, direct and reversible inhibitor of factor Xa that inhibits both free factor Xa and prothrombinase activity [40].

It is currently indicated for the prevention of stroke and systemic embolism in adult patients with NVAF with one or more risk factors and for the treatment of DVT and PE, as well as for the prevention of DVT and PE recurrence in adults [41-44], although its use in orthopedic surgery is not approved in Europe.

\section{Current evidence in cancer patients}

\section{Treatment of venous thromboembolic disease}

Real-world data studies show the use of DOACs in patients with active cancer, even before the publication of randomized controlled trials. Their results must be interpreted cautiously due to the potential selection bias inherent to observational studies of interventions. Weitz et al. [45], from the GARFIELD-VTE registry, reported $22.8 \%$ of patients with cancer receiving DOACs. Similarly, Streiff et al. [46] published a retrospective study including 707 patients treated with rivaroxaban compared with other cohorts treated with warfarin and LMWH, obtaining a trend for lower VTE recurrence rates in rivaroxaban users than in LMWH users at 6 months (13.2 vs. $17.1 \% ; p=0.060)$ and significantly lower recurrence rates at 12 months ( 16.5 vs. $22.2 \%$; $p=0.030)$ [HR 0.72, 95\% CI (0.52-0.95); $p=0.024]$. VTE recurrence rates were also lower for rivaroxaban users than for warfarin users at 6 months ( 13.2 vs. $17.5 \% ; p=0.014)$ and 12 months (15.7 vs. $19.9 \% ; p=0.017)$ [HR $0.74,95 \%$ CI $(0.56-0.96)$; $p=0.028$, with similar rates of major bleeding. Other studies have found that DOACs are at least as safe and effective as LMWH [47-53].

The main studies on DOACs are presented in Table 1. They included three studies conducted in the general population but reporting data of cancer patients, and 4 studies performed in cancer patients; in most cases, thrombosis recurrence was reported as the primary endpoint. The specific results of these studies are commented on in this section together with some pooled analyses and subanalyses. Phase III studies were designed to prove the efficacy of these drugs in the treatment of VTE in patients with various clinical conditions. These include the RE-COVER [23] and RE-COVER II [24] studies with dabigatran, the EINSTEIN-DVT study for DVT [54] and EINSTEIN-PE for PE [55] with rivaroxaban, and the AMPLIFY study [38] with apixaban (Table 1). The studies have the following main limitations: the small percentage of cancer patients included (5.5\%) and their heterogeneity in terms of cancer type, location and stage. The results showed similar efficacy, with greater safety in favor of DOACs compared to warfarin. Subanalysis of data from the oncology population has been conducted, and thus, Prins et al. [56] published a pooled analysis of the two studies with rivaroxaban (EINSTEIN-DVT and EINSTEIN-PE) selecting the oncology subpopulation. The authors concluded that DOACs were as effective and safe as heparin combined with VKA for the treatment of VTE in cancer patients. Within the evidence-based analysis, Vedovati et al. [57] conducted a 


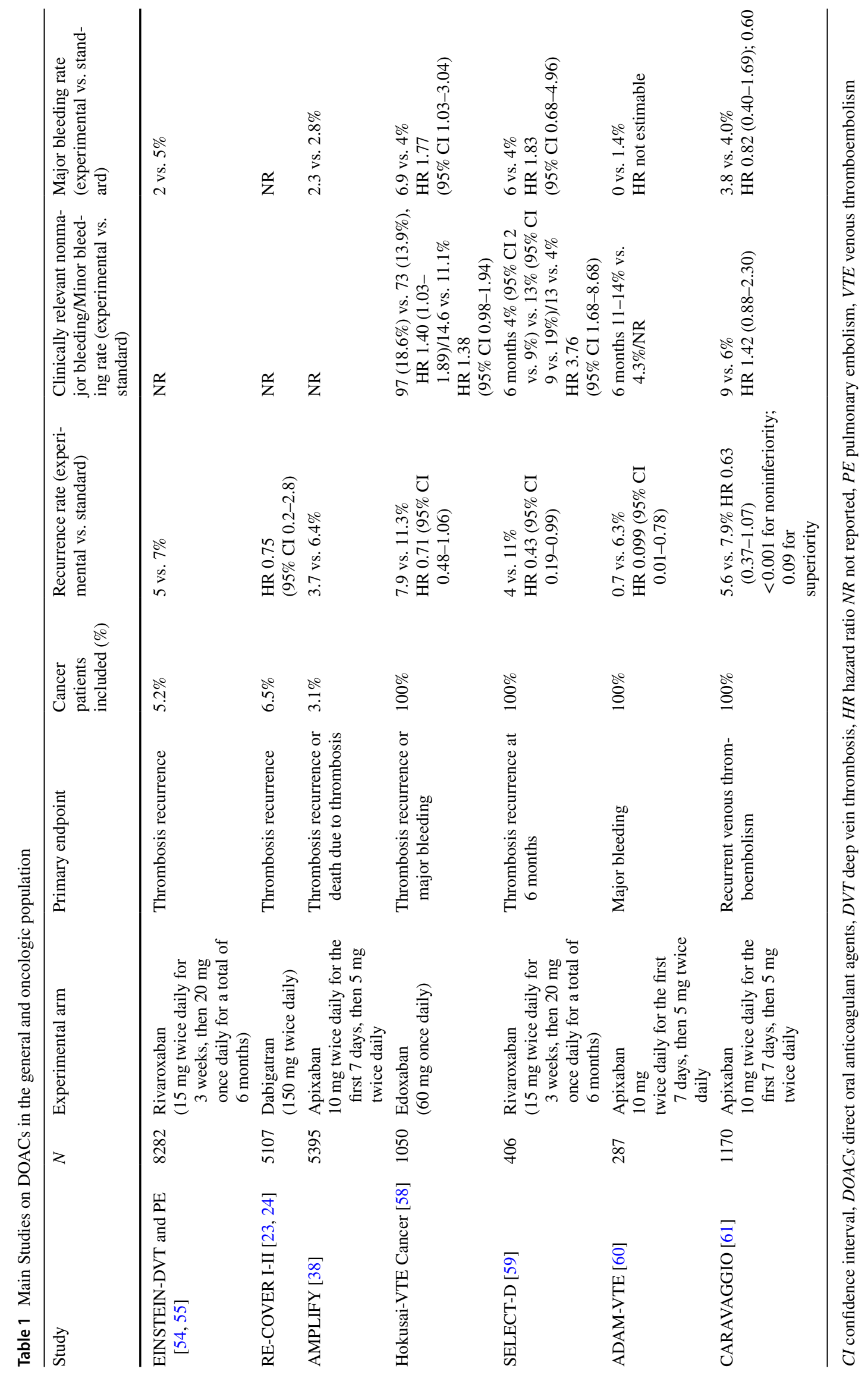


meta-analysis of randomized studies with DOACs assessing the safety and efficacy of DOACs in patients with thrombosis and cancer. Six randomized studies were included in the analysis: 2 with dabigatran, 2 with rivaroxaban, 1 with edoxaban and 1 with apixaban for a total of 1132 patients with thrombosis and active cancer. The comparator arm was LMWH followed by VKA. The recurrence of thrombosis in patients treated with DOACs was $3.9 \%$ vs. $6 \%$ for those treated with the standard of care (OR $0.63,95 \%$ CI 0.37-1.10). In terms of safety, the incidence of episodes of major bleeding was $3.2 \%$ in patients treated with DOACs vs. $4.2 \%$ in those on standard anticoagulation [odds ratio (OR): $0.77,95 \%$ CI $0.41-1.44]$.

However, the great advance in estimating the impact of new DOACs on a population with cancer has undoubtedly been the design and publication of randomized trials in the cancer population (Table 1). Raskob et al. [58] published the results of the Hokusai-VTE Cancer study, a phase III randomized noninferiority study comparing dalteparin (at dosages of $200 \mathrm{IU} / \mathrm{kg} /$ day for 1 month followed by $150 \mathrm{IU} /$ $\mathrm{kg} /$ day) versus oral edoxaban ( $60 \mathrm{mg}$ orally once daily) after the first 5 days of parenteral anticoagulant. A total of 1050 patients were randomized, with a median age of 65 years, and in $63 \%$ of cases, VTE appeared at the pulmonary level in the form of PE. The primary efficacy outcome of the study was the occurrence of recurrent thrombosis, and the primary safety outcome was major or clinically relevant nonmajor bleeding. The Hokusai-VTE Cancer study was conducted in cancer patients diagnosed with DVT in the popliteal, femoral or iliac vein or inferior vena cava or in those with PE. Patients treated with bevacizumab; patients with severe renal impairment $(\mathrm{CrCl}<30 \mathrm{ml} / \mathrm{min})$, vena cava filters, liver disorders, or major thrombocytopenia; and those receiving treatment with $100 \mathrm{mg}$ ASA, clopidogrel or NSAIDs were excluded. Treatment lasted a minimum of 6 months in both arms, with possible extension to 12 months. The primary outcome of the study was met: $12.8 \%$ of events in the edoxaban arm versus $13.5 \%$ in the dalteparin arm, with an HR of 0.97 (95\% CI $0.70-1.36 ; p=0.006$ for noninferiority and $p=0.87$ for superiority). Edoxaban also showed reduced thrombosis recurrence, but the difference did not reach statistical significance ( 7.9 vs. $11.3 \%$, HR $0.71, p=0.09$ ); a statistically significantly increased incidence of major bleeding was found with edoxaban (6.9 vs. $4 \%$, HR 1.77, $p=0.04$ ) compared to LMWH, which was attributable to a greater number of gastrointestinal (GI) bleeding events with edoxaban. Young et al. [59] published the results of the SELECTD study, a phase III comparative trial of rivaroxaban $(15 \mathrm{mg}$ twice daily for 3 weeks, followed by $20 \mathrm{mg}$ once daily for a total of 6 months) versus dalteparin (200 IU/kg for the first month and $150 \mathrm{IU} / \mathrm{kg}$ for the following 5 months) as a treatment for VTE. The primary outcome of the study was the recurrence of DVT at 6 months. Safety was assessed by major bleeding or clinically relevant bleeding rates. Initially, the study design included a late anticoagulation phase (6-12 months) with rivaroxaban versus placebo, but it was not carried out due to low initial recruitment. A total of 406 patients were included (203 in each group), 58\% of whom were patients with metastatic tumors. The rate of thrombosis recurrence was $11 \%$ for dalteparin and $4 \%$ for rivaroxaban, with an HR of 0.43 (95\% CI 0.19-0.99). In terms of safety, $4 \%$ of patients on dalteparin experienced an episode of major bleeding compared to $6 \%$ in the rivaroxaban group (nonsignificant HR of 1.83), with most bleeding episodes starting in the GI tract. In an interim analysis, the inclusion of patients with esophageal and gastric cancer was stopped due to an excess of major bleeding with rivaroxaban compared to dalteparin (36 vs. $12 \%$, respectively). In addition, clinically relevant nonmajor bleeding events were 3 times more common in the group receiving the oral anticoagulant rivaroxaban [4 vs. 13\%, HR 3.69 (95\% CI 1.63-8.69)].

The ADAM-VTE trial [60] was the first study comparing DOACs to LMWH in cancer patients with major bleeding as the primary endpoint. This clinical phase III randomized controlled superiority trial compared apixaban with dalteparin in 300 patients with cancer-associated VTE. In terms of the efficacy and secondary endpoint, apixaban was related to significantly lower VTE recurrence compared to dalteparin ( 0.7 vs. $6.3 \%$, respectively, HR $0.26,95 \%$ CI $0.09-0.80 ; p=0.02$ ). In terms of the safety and primary objective, major bleeding was not significantly different between the two arms ( 0 vs. $1.4 \%$; $p=0.01$ ), with a similar OS between both groups and quality of life favoring apixaban.

Recently, Li et al. [62] published a meta-analysis of studies that included cancer patients with VTE. Analyzing the two randomized studies (Hokusai-VTE Cancer and SELECT-D), edoxaban and rivaroxaban were compared with dalteparin, resulting in a tendency toward a lower recurrence in favor of DOACs (HR $0.65,95 \%$ CI $0.42-1.01$ ) and more frequent major bleeding in the group receiving oral anticoagulation versus LMWH (HR 1.74, 95\% CI 1.05-2.88) regarding safety. Clinically relevant nonmajor bleeding showed an increased risk without reaching statistical significance (HR 2.31, CI 0.85-6.28).

However, a meta-analysis of the Hokusai-VTE Cancer and SELECT-D studies observed increased bleeding complications, especially GI bleeds, in the DOAC arm. Subgroup analysis of the Hokusai-VTE Cancer trial described a higher risk of major bleeding events in the edoxaban arm compared to in the dalteparin arm (12.7 vs. 3.6\%; HR 4.0, 95\% CI 1.5-10.6; $p=0.005$ ), most of which were GI bleeds [63]. Soff et al. [64] recently reported a lower rate of bleeding in the DOAC arm in the Hokusai-VTE Cancer and SELECT-D trials excluding patients with GI or genitourinary malignancies. 
Finally, the results of the Caravaggio trial [61], a multinational, randomized, investigator-initiated, open-label, noninferiority trial with blinded central outcome adjudication that randomly assigned consecutive patients with cancer who had symptomatic or incidental acute proximal DVT or PE to receive oral apixaban (at a dosage of $10 \mathrm{mg}$ twice daily for the first 7 days, followed by $5 \mathrm{mg}$ twice daily) or subcutaneous dalteparin (at a dosage of 200 IU per kilogram of body weight once daily for the first month, followed by $150 \mathrm{IU}$ per kilogram once daily), have been published. The treatments were administered for 6 months. The primary outcome, recurrent VTE, was objectively confirmed during the trial period. The principal safety outcome was major bleeding. It randomized 1170 patients, and it is the largest trial ever conducted on cancer-associated thrombosis treatment. Patients with primary brain tumors, intracerebral metastases, or acute leukemia were not eligible. Recurrent VTE occurred in 32 of 576 patients $(5.6 \%)$ in the apixaban group and in 46 of 579 patients $(7.9 \%)$ in the dalteparin group (HR $0.63,95 \%$ CI $0.37-1.07 ; p<0.001$ for noninferiority). Major bleeding occurred in 22 patients (3.8\%) in the apixaban group and in 23 patients $(4.0 \%)$ in the dalteparin group (HR $0.82,95 \%$ CI $0.40-1.69 ; p=0.60$ ). Additionally, major GI bleeding was similar between arms, $1.9 \%$ in the apixaban arm versus $1.7 \%$ in the dalteparin arm. No difference in mortality was observed, with a death rate of any cause at 7 months of $3.4 \%$ for apixaban compared to $26.4 \%$ for dalteparin. However, event-free survival, defined as the absence of recurrent VTE, major bleeding or death, was superior for the apixaban arm: $73.3 \%$ versus $68.6 \%$ (HR 1.36, 95\% CI 1.05-1.76). The authors concluded that oral apixaban was noninferior to subcutaneous dalteparin for the treatment of cancer-associated VTED, without an increased risk of major bleeding.

\section{Treatment with direct oral anticoagulants in cancer patients with upper extremity deep vein thrombosis (UEDVT)}

Globally, UEDVT accounts for approximately $10 \%$ of all DVTs and can trigger both PE and postphlebitic syndromes in the arm. The prevalence of UEDVT is increasing due to the increased use of central venous catheters of the port-acath type, Hickman type, etc. in patients with cancer and chronic diseases [65, 66].

The effectiveness and safety of new DOACs is being studied in various studies in this group of patients, and the limitations are similar to those of lower limb DVT and PE in small series, with little representation of patients with cancer and heterogeneous populations in terms of tumor type and stage. The Swedish registry AuriculA [65] includes 55 patients with UEDVT treated with DOACs [46 patients with rivaroxaban, 7 with apixaban and 2 with dabigatran]. Of the 55 patients, $10(18 \%)$ had a malignancy.
After 6 months of DOAC treatment, there was 1 case of recurrence during treatment $(2 \%)$ and 2 cases of recurrences after the end of the treatment period (4\%). Only 1 patient (2\%) experienced a nonmajor bleeding episode.

\section{Rivaroxaban and apixaban in the initial treatment of acute venous thromboembolism of atypical location (VTE-AL) in cancer patients}

Approximately $4 \%$ of VTE cases include atypical locations, such as splenic, renal, gonadal and cerebral vein territories [67-71]. These locations, although less frequent, are relevant in clinical practice, as they are often associated with neoplastic processes and require more specialized knowledge to decide the need for anticoagulant treatment. The main problem with apixaban and rivaroxaban trials is that they include mostly patients with confirmed PE and/or proximal DVT of the lower limbs and exclude atypical locations [38, 54, 55].

There are few studies that assess the use of DOACs in atypical locations, which makes it difficult to draw conclusions about the use of DOACs in these locations and in cancer patients.

Between March 2013 and February 2017, the Mayo Clinic created a registry of VTE patients prospectively followed to assess the rates of recurrence, major bleeding, clinically relevant nonmajor bleeding and survival [72]. Portal, mesenteric, splenic, hepatic, renal, ovarian or brain venous sinus territories were defined as atypical locations. Out of the 36 patients identified in the VTE-AL registry receiving DOACs, 19 (52.8\%) had a malignancy, 13 (36.1\%) were on chemotherapy, and 11 (30.6\%) had undergone recent surgery. Of the 23 patients with VTE-AL who were on enoxaparin, $22(95.7 \%)$ had a malignancy, $12(52.2 \%)$ were on chemotherapy, and 6 (26.1\%) had undergone a recent surgery. The percentage of patients with malignancy and VTEAL who had received DOACs was significantly lower than the percentage of patients with malignancy and VTE who had received enoxaparin (52.8 vs. $95.7 \% ; p<0.001)$, a fact that already implies a selection bias that, together with the recording characteristics of the study, limits the possibility of drawing conclusions. The authors observed higher mortality rates in patients with VTE-AL treated with DOACs (21.5 per 100 person-years; 95\% CI 7.9-46.7) compared to those with VTE $(8.3 ; 95 \%$ CI $5.4-12.2 ; p=0.03)$. Mortality was higher in the VTE-AL group on DOACs than in the VTE-TL group [21.45 (95\% CI 7.87-46.69) vs. 8.26 (95\% CI $5.35,12.20) ; p=0.03]$. The authors concluded that neither the recurrence rate nor the bleeding from rivaroxaban and apixaban in the treatment of VTE-AL were different from the recurrence or bleeding rates of DOAC-treated VTE or enoxaparin-treated VTE-AL. 


\section{Primary prophylaxis of VTE}

Primary thromboprophylaxis is recommended in hospitalized patients with active cancers and is not recommended in the routine care of ambulatory patients treated with chemotherapy $[73,74]$. This indication should be considered for select high-risk patients considering the clinical and tumor characteristics [75-80] and the clinical prediction scores, such as Khorana et al. and others [77, 81, 82] who modify the original score, including the Protecht score [83] and Vienna score [84].

Some recently published clinical trials have reported results regarding the utility of DOACs in this setting (Table 2). The AVERT trial [85], a randomized, placebocontrolled, double-blind clinical trial, compared 6 months of $2.5 \mathrm{mg}$ apixaban twice daily with placebo in 574 patients with a Khorana score $\geq 2$. The primary efficacy outcome rate was lower in the apixaban group than in the placebo group (4.2 vs. $10.2 \%$; HR $0.41,95 \%$ CI $0.26-0.65$; $p<0.001 ; 17$ patients needed to be treated to avoid 1 episode of VTE). Major bleeding was higher in the apixaban group, except when the analysis was limited to the treatment period (2.1 vs. $1.1 \%$; HR $1.89,95 \%$ CI $0.39-9.24$ ). No fatal bleeds occurred, and no difference in nonmajor bleeding or mortality was observed. The CASSINI trial [86] was a double-blind, randomized, placebo-control multicenter study that compared rivaroxaban with placebo in 841 ambulatory patients with a Khorana score $\geq 2$. The primary endpoint (objectively confirmed VTE and death from VTE assessed up to day 180) occurred in $6 \%$ of patients in the rivaroxaban group and in $8.8 \%$ of patients in the placebo group (HR 0.66; 95\% CI $0.40-1.09 ; p=0.10$ ). During the on-treatment period, rivaroxaban significantly reduced the primary endpoint of VTE or VTE-related death compared with placebo ( 2.62 vs. $6.41 \%$; HR 0.40 , $95 \%$ CI $0.20-0.80 ; p=0.007$; with a number needed to treat of 26 patients). No difference was observed between groups during the analysis of the full observation period. The rates of major bleeding were similar in both groups (1.98 vs. $0.99 \%$; HR $1.96,95 \%$ CI $0.59-6.49 ; p=0.265$ ).

The results of these studies suggest that the included DOACs (apixaban and rivaroxaban) may reduce the rate of VTE as primary thromboprophylaxis in high-risk patients with an acceptable safety profile. Some limitations of these studies should be considered for future randomized trials, without avoiding the fact of the different inclusion and exclusion criteria of both studies as well as the use of expanded Khorana scores in the AVERT trial compared with the original Khorana scores in the CASSINI trial, as they provide specific knowledge on the risk and benefit of thromboprophylaxis in specific cancer types, the correct evaluation of bleeding risk considering that both studies

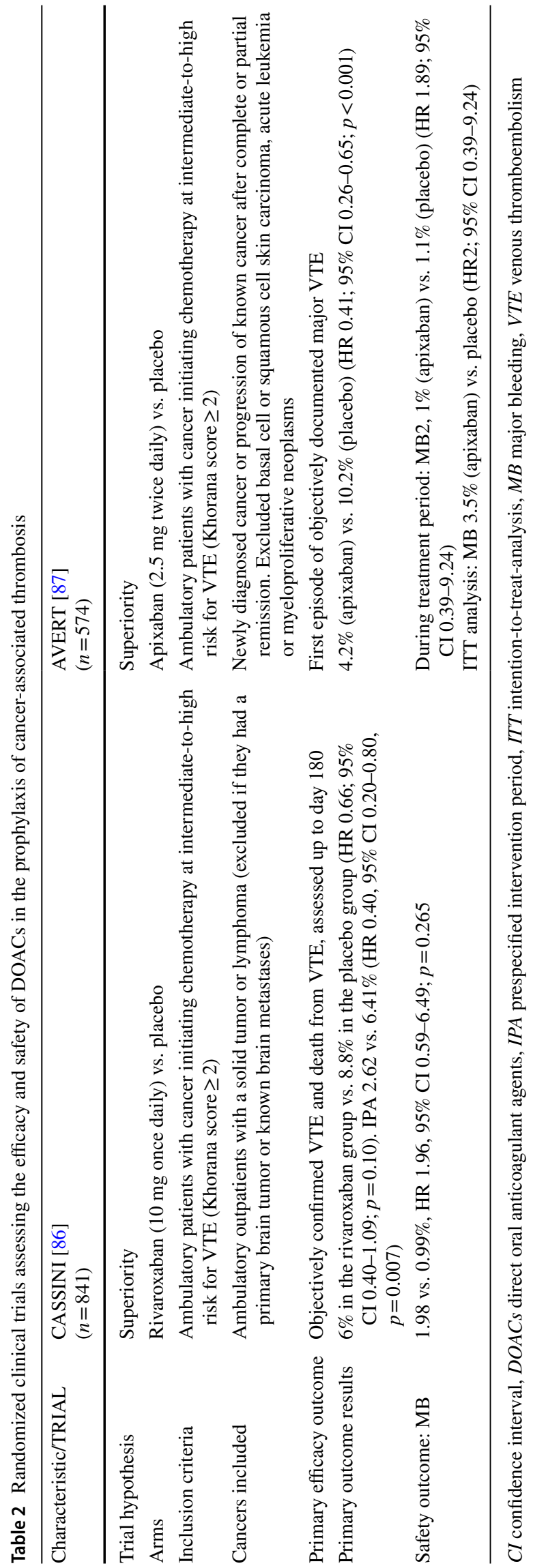


excluded patients at a high risk of bleeding, the duration of primary thromboprophylaxis in ambulatory cancer patients receiving chemotherapy with Khorana scores not validated for the risk stratification of patients at 6 months postchemotherapy initiation period, the usefulness of serial VTE screening image techniques in the care of patients and the consideration of the complexity of cancer patients and the multiple expectations that should be influenced before any intervention.

\section{Absorption, metabolism and potential interactions}

Due to oral administration and particularities in absorption, some aspects of DOAC metabolism and excretion may limit the use of these drugs. Considering absorption, rivaroxaban moderately interferes with food, requiring an intake of 15-20 mg. A minimal effect was observed with edoxaban, and no effect was observed with dabigatran and apixaban, although a rate of dyspepsia of 5-10\% was observed with dabigatran. Some authors have suggested fluoropyrimidineinduced GI damage that might reduce the plasma concentration of dabigatran by impairing absorption [87].

Regarding metabolism, apixaban, rivaroxaban and edoxaban, as well as substrates of cytochrome P450 isoenzyme $3 \mathrm{~A} 4$ to various degrees, with minimal interaction of edoxaban $(<4 \%$ excretion) and moderate interaction of apixaban (25\%), are also substrates of P-glycoprotein (P-gp), and the prodrug dabigatran etexilate is also a P-gp substrate. Strong inducers significantly decreased plasma DOAC levels, and strong inhibitors increased disease levels [88, 89]. Some anticancer drugs with potential interactions include tyrosine kinase inhibitors, antimitotic microtubules and some immune-modulating agents, including glucocorticoids [89]. Other interactions include cyclosporine increasing plasma levels of edoxaban [90] and some groups with potential interactions, such as anthracyclines, topoisomerase inhibitors, and alkylating and hormonal agents [89].

Other clinical situations that can cause interactions with DOACs are chemotherapy-induced nausea and vomiting [4] and alterations in renal function in which dabigatran and edoxaban have a renal clearance of 80 and $50 \%$, respectively; thus, careful dosing and drug labeling should be considered in patients with renal failure [91-94] and thrombocytopenia, considering anticoagulation in patients with $<25,000$ platelets/ $\mu \mathrm{l}$ who are at lower risk for recurrent VTE.

\section{Upcoming studies}

There are ongoing studies evaluating DOACs that will provide further evidence for the use of these agents in cancer patients and will help to clarify remaining questions. The CASTA-DIVA (NCT02746185) [37] study (rivaroxaban vs. dalteparin) for the treatment of VTE in patients with cancer and high risk of VTE recurrence has primary outcomes of recurrent VTE, major bleeding and clinically relevant nonmajor bleeding and mortality; the CANVAS trial (NCT027440923)36 (DOAC vs. LMWH or LMWH + VKA) has a primary outcome of cumulative VTE recurrence; the APICAT trial compares the efficacy and safety of two doses of apixaban for the extended treatment of VTE in cancer patients (breast, prostate and colon-rectum); the EVEExtended study compares the safety of two doses of apixaban for the extended treatment of cancer patients with VTE; and other studies such as COSIMO37 (NCT027426239), a prospective cohort study (patient-reported outcomes with rivaroxaban: a noninterventional study), and Conko-011 (NCT02583191) comparing rivaroxaban versus LMWH (patient-reported treatment satisfaction).

\section{Recommendations}

Based on the information reviewed, the following recommendations can be made:

1. According to the evidence described in this review, we cannot make specific recommendations for prophylaxis of VTE in hospitalized medical and surgical cancer patients.

2. Considering VTE prophylaxis in ambulatory cancer patients during systemic therapy assessment, the results of the AVERT and CASSINI trials suggest that, although routine thromboprophylaxis is not recommended (level of evidence: grade 1B), apixaban and rivaroxaban may reduce the rate of VTE via primary thromboprophylaxis in high-risk patients with an acceptable safety profile, such as in patients with advanced pancreatic cancer; patients with a Khorana score $\geq 2$ or patients considered high-risk based on a validated risk assessment model; patients who have initiated systemic therapy and no contraindications to anticoagulation; and patients with a low risk of bleeding. There is no consensus about the dose and duration of the thromboprophylaxis; it is suggested that it should last at least 12 weeks after the initiation a new systemic therapy. A specific drug-drug interaction assessment must be done.

3. In the treatment of VTE in cancer patients, although LMWH at a body weight-adjusted dose is the drug of choice for the initial treatment (level of evidence: grade 1B), DOACs can be an alternative in the treatment of these patients, especially in patients at low risk of bleeding (increased risk of GI and probably genitourinary bleeding), and they have no significant drug-drug interactions (level of evidence: grade 1A). Edoxaban and rivaroxaban are equally or more effective than dalteparin for the prevention of VTE recurrence but confer a higher 
risk for major bleeding, especially in GI cancers. The recent publication of the results of the Caravaggio trial presents apixaban as a good alternative in this group of patients considering efficacy and no increased risk of major bleeding (including GI major bleeding).

4. It is difficult to reach a conclusion for the treatment of VTE with DOACs in UEDVT, an atypical location, since these events were not included in the largest randomized clinical trials of DOACs (neither in analyses of cancer patients nor in subanalyses provided for this outcome).

5. A switch to DOACs can be a good alternative in the treatment of VTE recurrence (level of evidence: grade 2B). If recurrence occurs while under treatment with DOACs, a switch to LMWH should be considered; alternatively, DOAC dose escalation should be considered if an infratherapeutic dose was used (level of evidence: grade $3 \mathrm{C}$ ).

6. DOACs have emerged as an attractive alternative to LMWH in the treatment of VTE in cancer patients. All benefits and risks of each of these agents should be taken into consideration and evaluated in individual patients based on their risk-benefit profile, comorbidities and probable adherence to treatment. Furthermore, the risk of VTE also varies throughout the clinical course of cancer, and for this reason, the choice of anticoagulant should be considered in accordance with the current presence of robust data supporting the use of DOACs for the treatment and prevention of VTE in selected patients. GI and urothelial cancer patients require extreme caution due to the high rates of major bleeding. Even with the publication of new and ongoing studies, the evidence for DOAC treatment in cancer-associated VTE has limitations that should prompt further research: the patient selection for prior clinical trials may not reflect the entire patient population, there is little evidence on the optimal duration of anticoagulation, and there are doubts concerning which patients are most likely to benefit from DOAC therapy.

Acknowledgments The authors would like to thank Fernando RicoVillademoros (COCIENTE SL, Madrid, Spain) for his editorial assistance in the preparation of this manuscript. His participation has been funded by the Spanish Society of Medical Oncology.

Author contributions IG-E and AJMM led the conception, design, and coordination of this manuscript. All authors contributed to the design, writing, and critical revision of the manuscript. All authors approved the final version to be published before it was submitted.

Funding This project has been funded by the Spanish Society of Medical Oncology (SEOM).

\section{Compliance with ethical standards}

Conflict of interest IG-E has been an advisory board member for Leo Pharma and has received speaker honoraria from Leo Pharma. EB-V has received speaker honoraria from Leo Pharma and Rovi. VP has been an advisory board member for DAICHI and has received speaker honoraria from Sanofi and Leo Pharma. AJMM declares the following conflicts of interest: Advisory boards: Celgene, Astra-Zeneca, Roche, Servier, Sanofi, Pfizer, Bristol-Myers Squibb, Leo Pharma, Daiichi Sankyo, Bayer and Halozyme; Speaker's bureau: Rovi, Lilly, Merck Sharp \& Dohme; Research funding: Sanofi and Leo Pharma; Travel, Accommodations, Expenses: Celgene, Roche, Merck Serono, Amgen, Sanofi; Patents, royalties, other intellectual property: Risk assessment model in venous thromboembolism in patients with cancer. DGA and VM-M declare no conflicts of interest.

Ethical approval The manuscript does not contain any studies with human participants or animals performed by any of the authors.

Informed consent Informed consent/ethical approval was not required.

Open Access This article is licensed under a Creative Commons Attribution 4.0 International License, which permits use, sharing, adaptation, distribution and reproduction in any medium or format, as long as you give appropriate credit to the original author(s) and the source, provide a link to the Creative Commons licence, and indicate if changes were made. The images or other third party material in this article are included in the article's Creative Commons licence, unless indicated otherwise in a credit line to the material. If material is not included in the article's Creative Commons licence and your intended use is not permitted by statutory regulation or exceeds the permitted use, you will need to obtain permission directly from the copyright holder. To view a copy of this licence, visit http://creativecommons.org/licenses/by/4.0/.

\section{References}

1. Lee AY, Levine MN. Venous thromboembolism and cancer: risks and outcomes. Circulation. 2003;107:I17-21.

2. Falanga A, Russo L, Verzeroli C. Mechanisms of thrombosis in cancer. Thromb Res. 2013;131(Suppl 1):S59-S62.

3. Abdol Razak NB, Jones G, Bhandari M, Berndt MC, Metharom P. Cancer-associated thrombosis: an overview of mechanisms, risk factors, and treatment. Cancers (Basel). 2018;10:380.

4. Prandoni P, Lensing AW, Piccioli A, Bernardi E, Simioni P, Girolami B, Marchiori A, Sabbion P, Prins MH, Noventa F, Girolami A. Recurrent venous thromboembolism and bleeding complications during anticoagulant treatment in patients with cancer and venous thrombosis. Blood. 2002;100:3484-8.

5. Watson HG, Keeling DM, Laffan M, Tait RC, Makris M. Guideline on aspects of cancer-related venous thrombosis. Br J Haematol. 2015; 170:640-8.

6. Farge D, Bounameaux H, Brenner B, Cajfinger F, Debourdeau P, Khorana AA, Pabinger I, Solymoss S, Douketis J, Kakkar A. International clinical practice guidelines including guidance for direct oral anticoagulants in the treatment and prophylaxis of venous thromboembolism in patients with cancer. Lancet Oncol. 2016;17:e452-e466466.

7. Kearon C, Akl EA, Ornelas J, Blaivas A, Jimenez D, Bounameaux H, Huisman M, King CS, Morris TA, Sood N, Stevens SM, Vintch JRE, Wells P, Woller SC, Moores L. Antithrombotic therapy for 
VTE disease: CHEST guideline and expert panel report. Chest. 2016;149:315-52.

8. Delate T, Witt DM, Ritzwoller D, Weeks JC, Kushi L, Hornbrook MC, Aiello Bowles EJ, Schrag D. Outpatient use of low molecular weight heparin monotherapy for first-line treatment of venous thromboembolism in advanced cancer. Oncologist. 2012;17:419-27.

9. Kleinjan A, Hutten BA, Di Nisio M, Büller HR, Kamphuisen $\mathrm{PW}$. Anticoagulant treatment of cancer patients with pulmonary embolism in the real world. Actual use of low-molecular-weight heparin in cancer. Neth J Med. 2014;72:467-72.

10. Khorana AA, Yannicelli D, McCrae KR, Milentijevic D, Crivera C, Nelson WW, Schein JR. Evaluation of US prescription patterns: are treatment guidelines for cancer-associated venous thromboembolism being followed? Thromb Res. 2016;145:51-3.

11. Khorana AA, McCrae KR, Milentijevic D, Fortier J, Nelson WW, Laliberté F, Crivera C, Lefebvre P, Yannicelli D, Schein J. Current practice patterns and patient persistence with anticoagulant treatments for cancer-associated thrombosis. Res Pract Thromb Haemost. 2017;1:14-22.

12. Grandoni F, Alberio L. Direct oral anticoagulant drugs: on the treatment of cancer-related venous thromboembolism and their potential anti-neoplastic effect. Cancers (Basel). 2019;11:46.

13. Wittkowsky AK. Barriers to the long-term use of low-molecular weight heparins for treatment of cancer-associated thrombosis. J Thromb Haemost. 2006;4:2090-1.

14. van der Hulle T, Kooiman J, den Exter PL, Dekkers OM, Klok FA, Huisman MV. Effectiveness and safety of novel oral anticoagulants as compared with vitamin $\mathrm{K}$ antagonists in the treatment of acute symptomatic venous thromboembolism: a systematic review and meta-analysis. J Thromb Haemost. 2014;12:320-8.

15. Eriksson BI, Quinlan DJ. Oral anticoagulants in development: focus on thromboprophylaxis in patients undergoing orthopaedic surgery. Drugs. 2006;66:1411-29.

16. Eriksson BI, Dahl OE, Rosencher N, Kurth AA, van Dijk CN, Frostick SP, Kälebo P, Christiansen AV, Hantel S, Hettiarachchi R, Schnee J, Büller HR, RE-MODEL Study Group. Oral dabigatran etexilate vs. subcutaneous enoxaparin for the prevention of venous thromboembolism after total knee replacement the RE-MODEL randomized trial. J Thromb Haemost. 2007;5:2178-85.

17. Eriksson BI, Dahl OE, Rosencher N, Kurth AA, van Dijk CN, Frostick SP, Prins MH, Hettiarachchi R, Hantel S, Schnee J, Büller HR, RE-NOVATE Study Group. Dabigatran etexilate versus enoxaparin for prevention of venous thromboembolism after total hip replacement: a randomised, double-blind, non-inferiority trial. Lancet. 2007;370:949-56.

18. RE-MOBILIZE Writing Committee, Ginsberg JS, Davidson BL, Comp PC, Francis CW, Friedman RJ, Huo MH, Lieberman JR, Muntz JE, Raskob GE, Clements ML, Hantel S, Schnee JM, Caprini JA. Oral thrombin inhibitor dabigatran etexilate vs North American enoxaparin regimen for prevention of venous thromboembolism after knee arthroplasty surgery. J Arthroplasty. 2009;24:1-9.

19. Eriksson BI, Dahl OE, Huo MH, Kurth AA, Hantel S, Hermansson K, Schnee JM, Friedman RJ, RE-NOVATE II Study Group. Oral dabigatran versus enoxaparin for thromboprophylaxis after primary total hip arthroplasty (RE-NOVATE II*). A randomised, double-blind, non-inferiority trial. Thromb Haemost. 2011;105:721-9.

20. Venker BT, Ganti BR, Lin H, Lee ED, Nunley RM, Gage BF. Safety and efficacy of new anticoagulants for the prevention of venous thromboembolism after hip and knee arthroplasty: a metaanalysis. J Arthroplasty. 2017;32:645-52.

21. Connolly SJ, Ezekowitz MD, Yusuf S, Eikelboom J, Oldgren J, Parekh A, Pogue J, Reilly PA, Themeles E, Varrone J, Wang S, Alings M, Xavier D, Zhu J, Diaz R, Lewis BS, Darius H, Diener
HC, Joyner CD, Wallentin L, RE-LY Steering Committee, and Investigators. Dabigatran versus warfarin in patients with atrial fibrillation. N Engl J Med. 2009;361:1139-51.

22. Connolly SJ, Wallentin L, Ezekowitz MD, Eikelboom J, Oldgren J, Reilly PA, Brueckmann M, Pogue J, Alings M, Amerena JV, Avezum A, Baumgartner I, Budaj AJ, Chen JH, Dans AL, Darius H, Di Pasquale G, Ferreira J, Flaker GC, Flather MD, Franzosi MG, Golitsyn SP, Halon DA, Heidbuchel H, Hohnloser SH, Huber K, Jansky P, Kamensky G, Keltai M, Kim SS, Lau CP, Le Heuzey JY, Lewis BS, Liu L, Nanas J, Omar R, Pais P, Pedersen KE, Piegas LS, Raev D, Smith PJ, Talajic M, Tan RS, Tanomsup S, Toivonen L, Vinereanu D, Xavier D, Zhu J, Wang SQ, Duffy CO, Themeles E, Yusuf S. The long-term multicenter observational study of dabigatran treatment in patients with atrial fibrillation (RELY-ABLE) study. Circulation. 2013;128:237-43.

23. Schulman S, Kearon C, Kakkar AK, Mismetti P, Schellong S, Eriksson H, Baanstra D, Schnee J, Goldhaber SZ, RE-COVER Study Group. Dabigatran versus warfarin in the treatment of acute venous thromboembolism. N Engl J Med. 2009;361:2342-52.

24. Schulman S, Kakkar AK, Goldhaber SZ, Schellong S, Eriksson H, Mismetti P, Christiansen AV, Friedman J, Le Maulf F, Peter N, Kearon C, RE-COVER II Trial Investigators. Treatment of acute venous thromboembolism with dabigatran or warfarin and pooled analysis. Circulation. 2014;129:764-72.

25. Schulman S, Kearon C, Kakkar AK, Schellong S, Eriksson H, Baanstra D, Kvamme AM, Friedman J, Mismetti P, Goldhaber SZ, RE-MEDY Trial Investigators, RE-SONATE Trial Investigators. Extended use of dabigatran, warfarin, or placebo in venous thromboembolism. N Engl J Med. 2013;368:709-18.

26. Bratsos S. Pharmacokinetic properties of rivaroxaban in healthy human subjects. Cureus. 2019;11:e5484.

27. Mega JL, Braunwald E, Wiviott SD, Bassand JP, Bhatt DL, Bode C, Burton P, Cohen M, Cook-Bruns N, Fox KA, Goto S, Murphy SA, Plotnikov AN, Schneider D, Sun X, Verheugt FW, Gibson CM, ATLAS ACS 2-TIMI 51 Investigators. Rivaroxaban in patients with a recent acute coronary syndrome. N Engl J Med. 2012;366:9-19.

28. Anand SS, Bosch J, Eikelboom JW, Connolly SJ, Diaz R, Widimsky P, Aboyans V, Alings M, Kakkar AK, Keltai K, Maggioni AP, Lewis BS, Störk S, Zhu J, Lopez-Jaramillo P, O’Donnell M, Commerford PJ, Vinereanu D, Pogosova N, Ryden L, Fox KAA, Bhatt DL, Misselwitz F, Varigos JD, Vanassche T, Avezum AA, Chen E, Branch K, Leong DP, Bangdiwala SI, Hart RG, Yusuf S, COMPASS Investigators. Rivaroxaban with or without aspirin in patients with stable peripheral or carotid artery disease: an international, randomised, double-blind, placebo-controlled trial. Lancet. 2018;391:219-29.

29. Eriksson BI, Borris LC, Dahl OE, Haas S, Huisman MV, Kakkar AK, Muehlhofer E, Dierig C, Misselwitz F, Kälebo P, ODIXa-HIP Study Investigators. A once-daily, oral, direct factor Xa inhibitor, rivaroxaban (BAY 59-7939), for thromboprophylaxis after total hip replacement. Circulation. 2006;114:2374-81.

30. Eriksson BI, Borris LC, Friedman RJ, Haas S, Huisman MV, Kakkar AK, Bandel TJ, Beckmann H, Muehlhofer E, Misselwitz F, Geerts W, RECORD1 Study Group. Rivaroxaban versus enoxaparin for thromboprophylaxis after hip arthroplasty. N Engl J Med. 2008;358:2765-75.

31. Kakkar AK, Brenner B, Dahl OE, Eriksson BI, Mouret P, Muntz J, Soglian AG, Pap AF, Misselwitz F, Haas S, RECORD2 Investigators. Extended duration rivaroxaban versus short-term enoxaparin for the prevention of venous thromboembolism after total hip arthroplasty: a double-blind, randomised controlled trial. Lancet. 2008;372:31-9.

32. Lassen MR, Ageno W, Borris LC, Lieberman JR, Rosencher N, Bandel TJ, Misselwitz F, Turpie AG, RECORD3 Investigators. 
Rivaroxaban versus enoxaparin for thromboprophylaxis after total knee arthroplasty. N Engl J Med. 2008;358:2776-86.

33. Turpie AG, Lassen MR, Davidson BL, Bauer KA, Gent M, Kwong LM, Cushner FD, Lotke PA, Berkowitz SD, Bandel TJ, Benson A, Misselwitz F, Fisher WD, RECORD4 Investigators. Rivaroxaban versus enoxaparin for thromboprophylaxis after total knee arthroplasty (RECORD4): a randomised trial. Lancet. 2009;373:1673-80.

34. Patel MR, Mahaffey KW, Garg J, Pan G, Singer DE, Hacke W, Breithardt G, Halperin JL, Hankey GJ, Piccini JP, Becker RC, Nessel CC, Paolini JF, Berkowitz SD, Fox KA, Califf RM, ROCKET AF Investigators. Rivaroxaban versus warfarin in nonvalvular atrial fibrillation. N Engl J Med. 2011;365:883-91.

35. Bruins Slot KM, Berge E. Factor Xa inhibitors versus vitamin $\mathrm{K}$ antagonists for preventing cerebral or systemic embolism in patients with atrial fibrillation. Cochrane Database Syst Rev. 2018;3:CD008980.

36. Gumprecht J, Domek M, Lip GYH. A drug safety evaluation of apixaban for the treatment of atrial fibrillation, acute coronary syndrome, and percutaneous coronary intervention. Expert Opin Drug Saf. 2019;18:1119-25.

37. Granger CB, Alexander JH, McMurray JJ, Lopes RD, Hylek EM, Hanna M, Al-Khalidi HR, Ansell J, Atar D, Avezum A, Bahit MC, Diaz R, Easton JD, Ezekowitz JA, Flaker G, Garcia D, Geraldes M, Gersh BJ, Golitsyn S, Goto S, Hermosillo AG, Hohnloser SH, Horowitz J, Mohan P, Jansky P, Lewis BS, Lopez-Sendon JL, Pais P, Parkhomenko A, Verheugt FW, Zhu J, Wallentin L, ARISTOTLE Committees, and Investigators. Apixaban versus warfarin in patients with atrial fibrillation. $\mathrm{N}$ Engl J Med. 2011;365:981-92.

38. Agnelli G, Buller HR, Cohen A, Curto M, Gallus AS, Johnson M, Masiukiewicz U, Pak R, Thompson J, Raskob GE, Weitz JI, AMPLIFY Investigators. Oral apixaban for the treatment of acute venous thromboembolism. N Engl J Med. 2013;369:799-808.

39. Agnelli G, Buller HR, Cohen A, Curto M, Gallus AS, Johnson M, Porcari A, Raskob GE, Weitz JI, AMPLIFY-EXT Investigators. Apixaban for extended treatment of venous thromboembolism. N Engl J Med. 2013;368:699-708.

40. Rojas-Hernandez CM, Oo TH. Direct oral anticoagulants in the prevention and treatment of venous thromboembolism in patients with cancer: new insights from randomized controlled trials. Drugs. 2019;79:621-31.

41. Fuji T, Wang CJ, Fujita S, Kawai Y, Nakamura M, Kimura T, Ibusuki K, Ushida H, Abe K, Tachibana S. Safety and efficacy of edoxaban, an oral factor Xa inhibitor, versus enoxaparin for thromboprophylaxis after total knee arthroplasty: the STARS E-3 trial. Thromb Res. 2014;134:1198-204.

42. Fuji T, Fujita S, Kawai Y, Nakamura M, Kimura T, Fukuzawa M, Abe K, Tachibana S. Efficacy and safety of edoxaban versus enoxaparin for the prevention of venous thromboembolism following total hip arthroplasty: STARS J-V. Thromb J. 2015;13:27.

43. Giugliano RP, Ruff CT, Braunwald E, Murphy SA, Wiviott SD, Halperin JL, Waldo AL, Ezekowitz MD, Weitz JI, Špinar J, Ruzyllo W, Ruda M, Koretsune Y, Betcher J, Shi M, Grip LT, Patel SP, Patel I, Hanyok JJ, Mercuri M, Antman EM, ENGAGE AF-TIMI 48 Investigators. Edoxaban versus warfarin in patients with atrial fibrillation. N Engl J Med. 2013;369:2093-104.

44. Hokusai-VTE Investigators, Büller HR, Décousus H, Grosso MA, Mercuri M, Middeldorp S, Prins MH, Raskob GE, Schellong SM, Schwocho L, Segers A, Shi M, Verhamme P, Wells P. Edoxaban versus warfarin for the treatment of symptomatic venous thromboembolism. N Engl J Med. 2013;369:1406-15.

45. Weitz J, Turpie A, Haas S. Clinical characteristics and initial treatment of patients with cancer-associated venous thromboembolism: results from the GARFIELD-VTE registry. Res Pract Thromb Haemost. 2017;1:916-7.
46. Streiff MB, Milentijevic D, McCrae K, Yannicelli D, Fortier J, Nelson WW, Laliberté F, Crivera C, Lefebvre P, Schein J, Khorana AA. Effectiveness and safety of anticoagulants for the treatment of venous thromboembolism in patients with cancer. Am J Hematol. 2018;93:664-71.

47. Phelps MK, Wiczer TE, Erdeljac HP, Van Deusen KR, Porter K, Philips G, Wang TF. A single center retrospective cohort study comparing low-molecular-weight heparins to direct oral anticoagulants for the treatment of venous thromboembolism in patients with cancer - a real world experience. J Oncol Pharm Pract. 2019;25:793-800.

48. Simmons B, Wysokinski W, Saadiq RA, Bott-Kitslaar D, Henkin S, Casanegra A, Lenz C, Daniels P, Bjarnason H, Vargas E, Hodge D, Holton SJ, Cerhan JR, Loprinzi C, McBane R. Efficacy and safety of rivaroxaban compared to enoxaparin in treatment of cancer-associated venous thromboembolism. Eur J Haematol. 2018;101:136-42. https://doi.org/10.1111/ejh.13074.

49. Alzghari SK, Seago SE, Garza JE, Hashimie YF, Baty KA, Evans MF, Shaver C, Herrington JD. Retrospective comparison of low molecular weight heparin vs. warfarin vs. oral Xa inhibitors for the prevention of recurrent venous thromboembolism in oncology patients: the Re-CLOT study. J Oncol Pharm Pract. 2018;24:494-500.

50. Ianotto JC, Couturier MA, Galinat H, Mottier D, Berthou C, Guillerm G, Lippert E, Delluc A. Administration of direct oral anticoagulants in patients with myeloproliferative neoplasms. Int J Hematol. 2017;106:517-21.

51. Nicklaus MD, Ludwig SL, Kettle JK. Recurrence of malignancyassociated venous thromboembolism among patients treated with rivaroxaban compared to enoxaparin. J Oncol Pharm Pract. 2018;24:185-9.

52. Pritchard ER, Murillo JR, Putney D, Hobaugh EC. Single-center, retrospective evaluation of safety and efficacy of direct oral anticoagulants versus low-molecular-weight heparin and vitamin K antagonist in patients with cancer. J Oncol Pharm Pract. 2019;25:52-9.

53. Ross JA, Miller MM, Rojas Hernandez CM. Comparative effectiveness and safety of direct oral anticoagulants (DOACs) versus conventional anticoagulation for the treatment of cancer-related venous thromboembolism: a retrospective analysis. Thromb Res. 2017;150:86-9.

54. EINSTEIN Investigators, Bauersachs R, Berkowitz SD, Brenner B, Buller HR, Decousus H, Gallus AS, Lensing AW, Misselwitz F, Prins MH, Raskob GE, Segers A, Verhamme P, Wells P, Agnelli G, Bounameaux H, Cohen A, Davidson BL, Piovella F, Schellong S. Oral rivaroxaban for symptomatic venous thromboembolism. N Engl J Med. 2010;363:2499-510.

55. EINSTEIN-PE Investigators, Büller HR, Prins MH, Lensin AW, Decousus H, Jacobson BF, Minar E, Chlumsky J, Verhamme P, Wells P, Agnelli G, Cohen A, Berkowitz SD, Bounameaux H, Davidson BL, Misselwitz F, Gallus AS, Raskob GE, Schellong $\mathrm{S}$, Segers A. Oral rivaroxaban for the treatment of symptomatic pulmonary embolism. N Engl J Med. 2012;366:1287-97.

56. Prins MH, Lensing AW, Brighton TA, Lyons RM, Rehm J, Trajanovic M, Davidson BL, Beyer-Westendorf J, Pap ÁF, Berkowitz SD, Cohen AT, Kovacs MJ, Wells PS, Prandoni P. Oral rivaroxaban versus enoxaparin with vitamin $\mathrm{K}$ antagonist for the treatment of symptomatic venous thromboembolism in patients with cancer (EINSTEIN-DVT and EINSTEIN-PE): a pooled subgroup analysis of two randomised controlled trials. Lancet Haematol. 2014;1:e37-46.

57. Vedovati M, Germini F, Agnelli G, Becattini C. Direct oral anticoagulants in patients with VTE and cancer: a systematic review and meta-analysis. Chest. 2015;147:475-83.

58. Raskob GE, van Es N, Verhamme P, Carrier M, Di Nisio M, Garcia D, Grosso MA, Kakkar AK, Kovacs MJ, Mercuri MF, Meyer 
G, Segers A, Shi M, Wang TF, Yeo E, Zhang G, Zwicker JI, Weitz JI, Büller HR. Edoxaban for the treatment of cancer-associated venous thromboembolism. N Engl J Med. 2018;378:615-24.

59. Young AM, Marshall A, Thirlwall J, Chapman O, Lokare A, Hill C, Hale D, Dunn JA, Lyman GH, Hutchinson C, MacCallum P, Kakkar A, Hobbs FDR, Petrou S, Dale J, Poole CJ, Maraveyas A, Levine M. Comparison of an oral factor Xa inhibitor with low molecular weight heparin in patients with cancer with venous thromboembolism: results of a randomized trial (SELECT-D). J Clin Oncol. 2018;36:2017-23.

60. McBane Ii R, Loprinzi CL, Ashrani A, Perez-Botero J, Leon Ferre RA, Henkin S, Lenz CJ, Le-Rademacher JG, Wysokinski WE. Apixaban and dalteparin in active malignancy associated venous thromboembolism. The ADAM VTE trial. Thromb Haemost. 2017;117:1952-61.

61. Agnelli G, Becattini C, Meyer G, Muñoz A, Huisman MV, Connors JM, Cohen A, Bauersachs R, Brenner B, Torbicki A, Sueiro MR, Lambert C, Gussoni G, Campanini M, Fontanella A, Vescovo G, Verso M, Caravaggio Investigators. Apixaban for the treatment of venous thromboembolism associated with cancer. N Engl J Med. 2020;382:1599-607.

62. Li A, Garcia DA, Lyman GH, Carrier M. Direct oral anticoagulant (DOAC) versus low-molecular-weight heparin (LMWH) for treatment of cancer associated thrombosis (CAT): a systematic review and meta-analysis. Thromb Res. 2019;173:158-63.

63. Kraaijpoel N, Di Nisio M, Mulder FI, van Es N, Beyer-Westendorf J, Carrier M, Garcia D, Grosso M, Kakkar AK, Mercuri MF, Middeldorp S, Hernandez CR, Santamaria A, Schwocho L, Segers A, Verhamme P, Wang TF, Weitz JI, Zhang G, Zwicker JI, Büller HR, Raskob GE. Clinical impact of bleeding in cancer-associated venous thromboembolism: results from the Hokusai VTE cancer study. Thromb Haemost. 2018;118:1439-49.

64. Soff GA, Sarasohn DMM, Haegler-Laube ES, Devlin SM, Miao Y, Bendheim G, Batista J, Wills J, Mones JV, Wilkins C, Mantha $\mathrm{SH}$. Safe and effective use of rivaroxaban for treatment of cancer associated venous thromboembolic disease. In: 2018 Annual meeting of the American society for hematology. San Diego, CA; December 2018.

65. Muñoz FJ, Mismetti P, Poggio R, Valle R, Barrón M, Guil M, Monreal M. Clinical outcome of patients with upper-extremity deep vein thrombosis: results from the RIETE registry. Chest. 2008;133:143-8.

66. Isma N, Svensson PJ, Gottsäter A, Lindblad B. Upper extremity deep venous thrombosis in the population-based Malmö thrombophilia study (MATS). Epidemiology, risk factors, recurrence risk, and mortality. Thromb Res. 2010;125:e335-e33838.

67. Tafur AJ, Kalsi H, Wysokinski WE, McBane RD, Ashrani AA, Marks RS, Crusan DJ, Petterson TM, Bailey KR, Heit JA. The association of active cancer with venous thromboembolism location: a population-based study. Mayo Clin Proc. 2011;86:25-30.

68. Thatipelli MR, McBane RD, Hodge DO, Wysokinski WE. Survival and recurrence in patients with splanchnic vein thromboses. Clin Gastroenterol Hepatol. 2010;8:200-5.

69. Wysokinski WE, Gosk-Bierska I, Greene EL, Grill D, Wiste H, McBane RD 2nd. Clinical characteristics and long-term followup of patients with renal vein thrombosis. Am J Kidney Dis. 2008;51:224-32.

70. Lenz CJ, Wysokinski WE, Henkin S, Cohoon KP, Casanegra A, Simmons BS, Saadiq RA, Daniels PR, Wysokinska EM, Bjarnason $\mathrm{H}, \mathrm{McBane} \mathrm{RD}$. Ovarian vein thrombosis: incidence of recurrent venous thromboembolism and survival. Obstet Gynecol. 2017; 130:1127-35.

71. Gosk-Bierska I, Wysokinski W, Brown RD Jr, Karnicki K, Grill D, Wiste H, Wysokinska E, McBane RD 2nd. Cerebral venous sinus thrombosis: incidence of venous thrombosis recurrence and survival. Neurology. 2006;67:814-9.
72. Janczak DT, Mimier MK, McBane RD, Kamath PS, Simmons BS, Bott-Kitslaar DM, Lenz CJ, Vargas ER, Hodge DO, Wysokinski WE. Rivaroxaban and apixaban for initial treatment of acute venous thromboembolism of atypical location. Mayo Clin Proc. 2018;93:40-7.

73. Lyman G, Bohlke K, Falanga A, American Society of Clinical Oncology. Venous thromboembolism prophylaxis and treatment in patients with cancer: American Society of Clinical Oncology clinical practice guideline update. J Oncol Pract. 2015;11:e442-e44444.

74. Wang TF, Li A, Garcia D. Managing thrombosis in cancer patients. Res Pract Thromb Haemost. 2018;2:429-38.

75. Khorana AA, Francis CW, Culakova E, Kuderer NM, Lyman GH. Frequency, risk factors, and trends for venous thromboembolism among hospitalized cancer patients. Cancer. 2007;110:2339-466.

76. Lyman GH, Khorana AA, Falanga A, Clarke-Pearson D, Flowers C, Jahanzeb M, Kakkar A, Kuderer NM, Levine MN, Liebman H, Mendelson D, Raskob G, Somerfield MR, Thodiyil P, Trent D, Francis CW. American Society of Clinical Oncology guideline: recommendations for venous thromboembolism prophylaxis and treatment in patients with cancer. J Clin Oncol. 2007;25:5490-505.

77. Khorana AA, Kuderer NM, Culakova E, Lyman GH, Francis CW. Development and validation of a predictive model for chemotherapy-associated thrombosis. Blood. 2008;111:4902-7.

78. Khorana AA, Kamphuisen PW, Meyer G, Bauersachs R, Janas MS, Jarner MF, Lee AY. Tissue factor as a predictor of recurrent venous thromboembolism in malignancy: biomarker analyses of the CATCH trial. J Clin Oncol. 2017;35:1078-85.

79. Khorana AA, Rao MV. Approaches to risk-stratifying cancer patients for venous thromboembolism. Thromb Res. 2007;120:S41-50.

80. Ay C, Simanek R, Vormittag R, Dunkler D, Alguel G, Koder S, Kornek G, Marosi C, Wagner O, Zielinski C, Pabinger I. High plasma levels of soluble P-selectin are predictive of venous thromboembolism in cancer patients: results from the Vienna Cancer and Thrombosis Study (CATS). Blood. 2008;112:2703-8.

81. Parker A, Peterson E, Lee AYY, de Wit C, Carrier M, Polley G, Tien J, Wu C. Risk stratification for the development of venous thromboembolism in hospitalized patients with cancer. J Thromb Haemost. 2018;16:1321-6.

82. Patell R, Rybicki L, McCrae KR, Khorana AA. Predicting risk of venous thromboembolism in hospitalized cancer patients: utility of a risk assessment tool. Am J Hematol. 2017;92:501-7.

83. Verso M, Agnelli G, Barni S, Gasparini G, LaBianca R. A modified Khorana risk assessment score for venous thromboembolism in cancer patients receiving chemotherapy: the Protecht score. Intern Emerg Med. 2012;7:291-2.

84. Ay C, Dunkler D, Marosi C, Chiriac AL, Vormittag R, Simanek R, Quehenberger P, Zielinski C, Pabinger I. Prediction of venous thromboembolism in cancer patients. Blood. 2010;116:5377-82.

85. Carrier M, Abou-Nassar K, Mallick R, Tagalakis V, Shivakumar S, Schattner A, Kuruvilla P, Hill D, Spadafora S, Marquis K, Trinkaus M, Tomiak A, Lee AYY, Gross PL, Lazo-Langner A, El-Maraghi R, Goss G, Le Gal G, Stewart D, Ramsay T, Rodger M, Witham D, Wells PS. Apixaban to prevent venous thromboembolism in patients with cancer. N Engl J Med. 2019;380:711-9.

86. Khorana AA, Soff GA, Kakkar AK, Vadhan-Raj S, Riess H, Wun T, Streiff MB, Garcia DA, Liebman HA, Belani CP, O'Reilly EM, Patel JN, Yimer HA, Wildgoose P, Burton P, Vijapurkar U, Kaul S, Eikelboom J, McBane R, Bauer KA, Kuderer NM, Lyman GH. Rivaroxaban for thromboprophylaxis in high-risk ambulatory patients with cancer. N Engl J Med. 2019;380:720-8.

87. Tsujii K, Hattori $\mathrm{T}$, Imaoka A, Akiyoshi $\mathrm{T}$, Ohtani $\mathrm{H}$. 5-Fluororacil-induced gastrointestinal damage impairs the 
absorption and anticoagulant effects of dabigatran etexilate. J Pharm Sci. 2018;107:1430-3.

88. Riess H, Prandoni P, Harder S, Kreher S, Bauersachs R. Direct oral anticoagulants for the treatment of venous thromboembolism in cancer patients: potential for drug-drug interactions. Crit Rev Oncol Hematol. 2018;132:169-79.

89. Short NJ, Connors JM. New oral anticoagulants and the cancer patient. Oncologist. 2014;19:82-93.

90. Parasrampuria DA, Mendell J, Shi M, Matsushima N, Zahir $\mathrm{H}$, Truitt K. Edoxaban drug-drug interactions with ketoconazole, erythromycin, and cyclosporine. Br J Clin Pharmacol. 2016;82:1591-600.

91. Boehringer Ingelheim Pharmaceutical Inc. PRADAXA® (dabigatran etexilate mesylate) capsules for oral use Full prescribing information. Ridgefield: Boehringer Ingelheim Pharmaceuticals Inc; 2015.
92. Daiichi Sankyo Inc. SAVAYSA (edoxaban) tablets for oral use Full prescribing information. Parsippany: Daiichi Sankyo Inc; 2015.

93. Janssen Pharmaceuticals, Inc. XARELTO ${ }^{\circledR}$ (rivaroxaban) tablets for oral use Full prescribing information. Titusville: Janssen Pharmaceuticals, Inc.; 2016.

94. Bristol-Myers Squibb Company. ELIQUIS (apixaban) tablets for oral use. Full prescribing information. Princeton: Bristol-Myers Squibb Company; 2016.

Publisher's Note Springer Nature remains neutral with regard to jurisdictional claims in published maps and institutional affiliations. 